\title{
Cascade Distillation Subsystem Development: Early Results From the Exploration Life Support Distillation Technology Comparison Test
}

\author{
Michael R. Callahan ${ }^{1}$ \\ Jacobs Technology, Houston, Texas 77058 \\ Vipul Patel ${ }^{2}$ \\ Honeywell International, Torrance, California 90504 \\ and \\ Karen D. Pickering ${ }^{3}$ \\ NASA - Johnson Space Center, Houston, Texas 77058
}

In 2009, the Cascade Distillation Subsystem (CDS) wastewater processor (Honeywell International, Torrance, California) was assessed in the National Aeronautics and Space Administration (NASA) Exploration Life Support (ELS) distillation comparison test. The purpose of the test was to collect data to support down-selection and development of a primary distillation technology for application in a lunar outpost water recovery system. The CDS portion of the comparison test was conducted between May 6 and August 19, 2009. The system was challenged with two pretreated test solutions, each intended to represent a feasible wastewater generated in a surface habitat. The 30-day equivalent wastewater loading volume for a crew of four was intended to be processed for each wastewater solution. Test Solution 1 consisted of a mixed stream containing human-generated urine and humidity condensate. Test Solution 2 contained the addition of human-generated hygiene wastewater to the solution 1 waste stream components. Approximately $1500 \mathrm{~kg}$ of total wastewater was processed through the CDS during testing. Respective recoveries per solution were $93.4 \pm 0.7$ and $90.3 \pm 0.5$ percent. The average specific energy of the system during testing was calculated to be less than $120 \mathrm{~W}-\mathrm{hr} / \mathrm{kg}$. The following paper provides detailed information and data on the performance of the CDS as challenged per the ELS distillation comparison test.

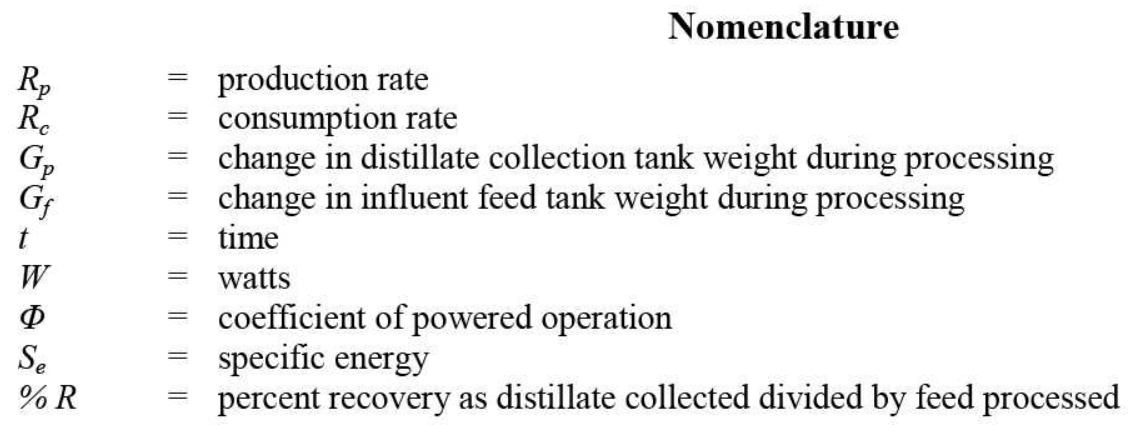

\footnotetext{
${ }^{1}$ Principal Investigator, Engineer and Science Contract Group, 2224 Bay Area Boulevard/JE-77.

${ }^{2}$ Principal Engineer, Advanced Technologies, $2525 \mathrm{~W} 190^{\text {th }}$ Street.

${ }^{3}$ Lead, Water Hardware and Technology Development Group, EC3/Crew and Thermal Systems Division, 2101 NASA Parkway.
} 


\section{Introduction}

$\mathrm{T}$ HE National Aeronautics and Space Administration (NASA) Vision for Space Exploration (VSE) proposes a series of human missions culminating in a permanent outpost on the Moon and missions to the Martian surface. ${ }^{1,2}$ Long-duration missions, such as those proposed in the VSE, will require the recovery of water from wastewater. Physicochemical processing systems, in particular distillation systems, have emerged as a candidate technology for primary processing in a closed-loop water recovery system. The cascade distillation subsystem (CDS) is one of three distillation technologies being developed by the NASA Exploration Life Support (ELS) Project Office ${ }^{3-9}$ Cascade distillation technology has been in development for several years (Lubman et al. ${ }^{7}$ and references therein). In early 2000, Honeywell International (Torrance, California) sponsored and led the development of the cascade distiller (CD)-5, a new, high-capacity, five-stage rotary vacuum distillation machine. In 2003, Honeywell received funding through NASA as part of a Rapid Technology Development Team (RTDT) program, NRA 03-OPBR-01. The objective of the RTDT is to promote the CDS as a candidate water recovery technology for the support of long-duration space missions. The CDS project is currently in its fifth year. Over the past 4 years, the project has moved through several stages, including requirements development, breadboard system testing, prototype design and fabrication, and checkout testing at Honeywell. In March 2007, a development unit was delivered to the NASA Johnson Space Center (JSC) Advanced Water Recovery Systems Development Facility (AWRSDF) for performance testing. In 2009, the CDS participated in an ELS comparison test. The primary objective of the comparison test was to collect data to support the down-selection and development of a primary distillation technology for a lunar surface system. The CDS portion of the ELS distillation comparison test was conducted between May 6 and August 19,2009. This document provides CDS test data from the ELS distillation comparison test.

\section{Materials and Methods}

\section{A. Test Overview}

Per the ELS distillation comparison test requirements, the CDS was challenged with human-generated influent test solutions, hereinafter referred to as distillation comparison test solutions 1 and 2. Distillation comparison test solution 1 was a mix of pretreated waste streams containing, by weight, approximately 57-percent pretreated humidity condensate and 43-percent pretreated urine. Distillation comparison test solution 2 was a mix of three pretreated waste streams containing, by weight, approximately 18-percent humidity condensate, 14-percent urine, and 68-percent hygiene water. Each test solution was planned to be run in single test run series consisting of a 30-day equivalent wastewater load for a crew of four. These loads translated into targeted processing goals of $414 \mathrm{~kg}$ of ELS test solution 1 and $1283 \mathrm{~kg}$ of ELS test solution 2 . Each solution was to be processed at a minimum recovery rate specific to the test solution: 93.5 percent for test solution 1 and 90.0 percent for test solution 2. During testing, water quality and thermodynamic performance data were collected. In addition, detailed chemical analysis data was also collected in three separate batch runs from each 30-day test series. At the conclusion of each 30-day test series the distiller unit was disassembled and inspected.

\section{B. Description of the CDS Technology}

The CDS technology has been described previously ${ }^{6-8}$ A simplified schematic of the system is shown in Figure 1. In general, operation of the CDS involves evaporation and condensation of wastewater and brine within a rotating drum. The drum is divided into five distillation compartments by means of specially designed baffles. Influent feed and recycled brine solutions are fed into the rotating drum at various stages in the distillation process. The vapor formed in each distillation chamber is condensed on the surface of the partition opposite the next evaporation stage. Each of the five distillation compartments is maintained at a successively lower operating pressure, allowing the heat of vaporization to be recovered four times. A simplified model showing the process stream flow in the five-stage distillation engine is shown in Figure 2. To enhance the liquid evaporation process, an external thermoelectric heat pump (THP) is used to provide heat energy to the hot side of the liquid recirculation loop. The THP also provides cooling energy to the cold recirculation loop. The cooling energy is used to remove the heat of vaporization not recuperated from the process. A trimming heat exchanger provides additional cooling energy to balance the thermal inefficiencies common to THP technology. By operating at reduced pressure and recovering the latent heat of vaporization, the energy requirements of the CDS are conserved. In addition, the centrifugal forces produced during 
rotation of the drum assembly support the transport of all liquids within the system and the operation of the distiller at reduced gravity.

\section{CDS Test Operations}

General operation of the CDS was conducted according to procedures adapted from those provided by the CDS vendor at system delivery. Typical operating parameters included a rotation speed of 1200 RPM; system pressure maintenance between $2.1-4.1 \mathrm{kN} / \mathrm{m}^{2}$; and hot and cold loop recirculation rates of 1.4 and $1.5 \mathrm{~L} / \mathrm{min}$, respectively. Input power to the THP was $300 \mathrm{~W}$ for test solution 1, resulting in average hot and cold loop temperatures at the outlet of the THP of approximately $45{ }^{\circ} \mathrm{C}$ and $22{ }^{\circ} \mathrm{C}$, respectively; and a targeted steady-state production rate of $4 \mathrm{~kg} / \mathrm{hr}$. For test solution 2 the THP input power was maintained at $400 \mathrm{~W}$, resulting in average hot and cold loop temperatures at the outlet of the THP of approximately $42^{\circ} \mathrm{C}$ and $21^{\circ} \mathrm{C}$, respectively; and a targeted steady-state production rate of $5 \mathrm{~kg} / \mathrm{hr}$. Heat loss across the entire distillation engine was about $8-10{ }^{\circ} \mathrm{C}$. The chiller cart supplying cooling media to the trimming heat exchanger was set between 18 and $19{ }^{\circ} \mathrm{C}$, with a flow rate of approximately $2.8 \mathrm{~L} / \mathrm{min}$.

\section{Preparation of Test Solutions}

All wastewater streams used for CDS testing were generated according to requirements put forth in the ELS distillation comparison test plan. For CDS testing, urine was collected at NASAJSC from human donors and chemically stabilized using $5 \mathrm{~g}$ of Oxone (Sigma Aldrich), $2.3 \mathrm{~g}$ of concentrated sulfuric acid, and $250 \mathrm{~g}$ of deionized

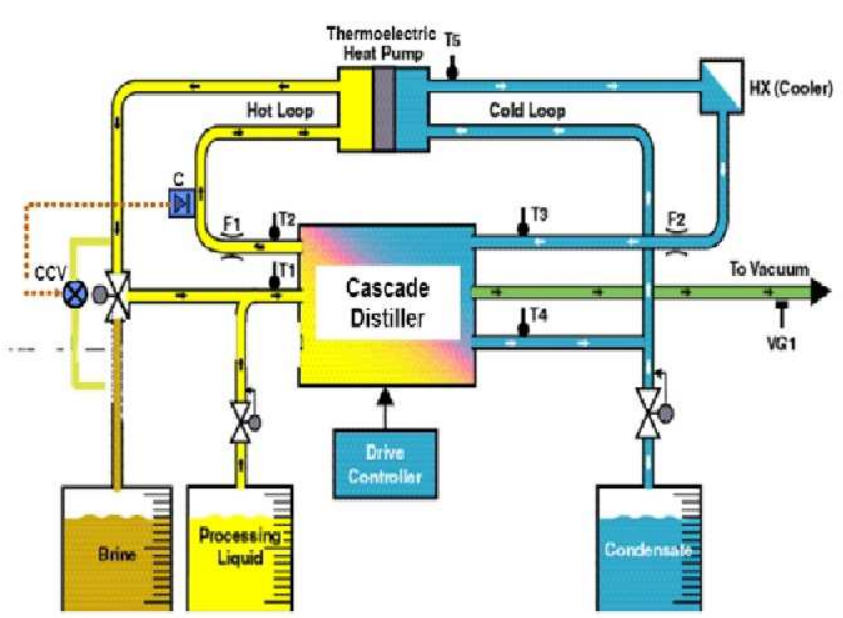

Figure 1. CDS Block Diagram

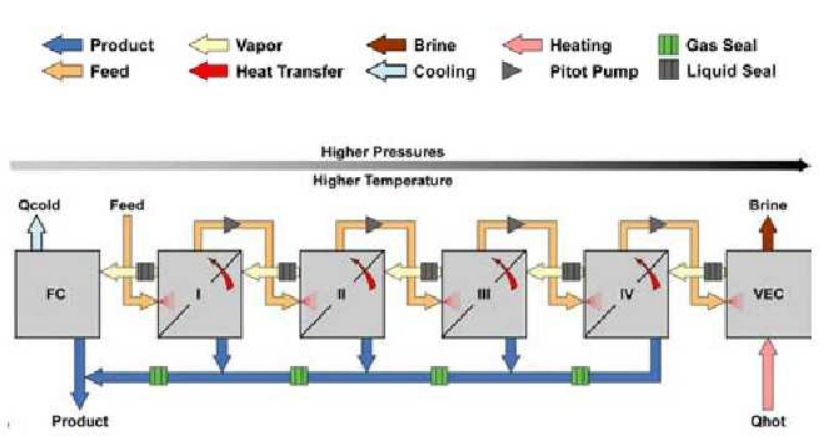

Figure 2. Steady-State Model CDS Distillation Engine (DI) flush water per liter of raw urine. Hygiene wastewater was collected from human volunteers using the Wastewater Transport and Collection System (WTCS) at NASA-JSC. Hygiene collection activities included showering, oral hygiene, and hand washing. Per person-day, hygiene wastewater specifications included $6 \mathrm{~kg}$ of shower water and $25 \mathrm{~g}$ of No Rinse Body Bath soap (Cleanlife Products, Springboro, Ohio); eight hand wash events, with $125 \mathrm{~g}$ of water and $1.5 \mathrm{~g}$ of No Rinse Body Bath soap; two oral hygiene events, with $100 \mathrm{~g}$ of water and $1 \mathrm{~g}$ of Orajel Fruit Splash Toddler Training Toothpaste (Church \& Dwight Company, Inc.); and a one-quarter shave event, with $150 \mathrm{~g}$ of water and $0.8 \mathrm{~g}$ of Neutrogena Men Skin Clearing Shave Cream (Johnson \& Johnson). The one-quarter shave event assumes that one crewmember out of four will prefer a wet shave versus a dry electric shave. The hygiene waste stream generated was chemically stabilized using $1 \mathrm{~g}$ of Oxone and $0.22 \mathrm{~g}$ of concentrated sulfuric acid per liter of hygiene water produced. Humidity condensate was generated from human participants exercising and conducting hygiene activities in the Regenerative Environmental Control and Life Support Module Simulator (REMS) at NASA's Marshall Space Flight Center (MSFC). The condensate was chemically stabilized with $0.5 \mathrm{~g}$ of Oxone and $0.11 \mathrm{~g}$ of concentrated sulfuric acid per liter solution produced. The humidity condensate was shipped to NASA-JSC's AWRSDF in support of the CDS portion of the distillation comparison test. Stock waste stream solutions of pretreated urine and hygiene water were maintained at room temperature, $21 \pm 4{ }^{\circ} \mathrm{C}$. Solutions of pretreated humidity condensate were delivered to the AWRSDF on ice and stored at $4 \pm 2{ }^{\circ} \mathrm{C}$ until their use. The pretreated humidity condensate, urine, and hygiene water were combined in a common carboy; each constituent waste stream was weighed and combined in the proper ratio for test solutions 1 and 2. The mixed waste streams were prepared in batches, 
one batch per test run. Residual influent from a previous batch run typically was added to the next prepared batch to maintain a relatively constant volume in the feed tank at the start of each test run. Prepared feed volumes averaged $15 \pm 2 \mathrm{~kg}$ for test solution 1 and $27 \pm 7 \mathrm{~kg}$ for test solution 2 . The mixed waste streams were generally prepared 4 to 12 hours prior to a test run. Solutions were brought to room temperature prior to use. The mixed waste streams were transferred from the common carboy to the CDS feed tank through a peristaltic pump. Filtration of the influent was provided during solution transfer by an inline, 100-micron stainless steel filter (McMaster Carr, P/N 474275K82) housed in a10-in. polycarbonate filter sump (Cole Palmer, P/N K-29820-10). The solutions were pumped to the CDS feed tank at a rate of approximately 1.5 $\mathrm{kg} / \mathrm{min}$.

\section{E. Sample Collection and Analysis}

Following each test run, approximately 300 to $500 \mathrm{~mL}$ of sample were collected from the feed and product tanks. The entire contents of the brine tank were collected in a tared sample bottle/carboy. Each process stream was collected from the sample port valve located at the base of the respective tanks. The entire contents of the two inline vapor traps also were collected in tared sample bottles. The mass of the liquid collected from the vapor traps and the brine tank was recorded per batch. The mass of the water collected from the vapor traps was added to the total mass of distillate produced during the run. The mass of the brine collected was used to calculate a system mass balance for the three process streams. A portion of each brine sample collected, approximately $250 \mathrm{~g}$, was poured into a separate sample bottle for chemical analysis. All samples-brine, product, influent, and vapor trap-were routinely analyzed for $\mathrm{pH}$, conductivity, anions/cations, total organic carbon (TOC), and total inorganic carbon (TIC). In addition, limited samples were collected for detailed water quality analysis of the influent, brine, and distillate. The analysis included metals, surface tension, total solids (TS), total dissolved solids (TDS), total suspended solids (TSS), total nitrogen (TN), and detailed organic analysis of volatiles, semivolatiles, nonvolatiles, alcohols, aldehydes, glycols, organic acids, ketones, and urea. Detailed organic analysis was performed by the Water and Food Analysis Laboratory (WAFAL) at JSC. Sample bottles for detailed organic analysis were provided by the WAFAL.

\section{F. Analytical Instrumentation}

Standard chemical analyses were obtained according to methods described in Methods for the Examination of Water and Wastewater ${ }^{10}$. These analysis included $\mathrm{pH}(4500-\mathrm{H}+\mathrm{B})$, conductivity $(2510 \mathrm{~B})$, turbidity (2130B) and solids analysis (2540 C\&D). $\mathrm{pH}$ measurements were made using an Orion $3 \mathrm{Star} \mathrm{pH}$ meter (P/N 1112000) equipped with an Orion glass body combination 8102BN Ross $\mathrm{pH}$ electrode. Conductivity measurements were made using an Orion 3 Star conductivity meter (P/N 1114000) equipped with a $013005 \mathrm{MD}$ conductivity probe. Turbidity measurements were made with a HACH 2100AN turbidimeter. Ion chromatography (IC) analyses were made using a Metrohm dual piston pump (model 709) with a Metrohm conductivity detector (model 732). A Cetac IC Sep AN1-SC and METROSEP Cation 1-2 IC columns were used for anion and cation analyses, respectively. Metals were measured using an Agilent 7500 Series inductively coupled plasma mass spectrometer (ICP-MS). TOC, TIC, and TN measurements were made using a Shimadzu TOC-V total organic carbon analyzer with ASI-V automatic sampler. Surface tension measurements were made using a Kruss K100 tensiometer..

\section{G. Calculations}

\section{Production Rate}

The production rate in kilograms per hour is given by

$$
R_{p}=\frac{G_{p}}{\Delta t}
$$

where $G_{p}$ is the weight of distillate measured by the product tank weight scale over the time interval $\Delta t$.

\section{Consumption Rate}

The consumption rate in kilograms per hour is given by

$$
R_{c}=\frac{G_{f}}{\Delta t}
$$


where $G_{f}$ is the change in the weight of feed solution as measured by the feed tank weight scale over the time interval $\Delta t$.

Power Consumption

The total power consumption in watts is given by

$$
W=W_{T H P} x \Phi_{T H P}+W_{C D} x \Phi_{C D}+W_{V A C} x \Phi_{V A C}
$$

where $W_{T H P}, W_{C D}$, and $W_{V A C}$ are the average power consumed by the THP, CD, and vacuum pump, respectively, during batch operation, and $\Phi_{T H P}, \Phi_{C D}$, and $\Phi_{V A C}$ are the respective ratios of operation over the total time interval considered, batch run or steady state. Full batch processing was considered to be the time from distiller startup to distiller shutdown. A steady-state condition was considered over the time period at which cooling media began to be supplied to the trimming heat exchanger to when the influent feed valve was closed at the end of the batch run.

$\underline{\text { Specific Energy }}$

The specific energy $\left(S_{e}\right)$ consumption watt-hours per kilogram of water produced is given by

$$
S_{e}=\frac{W}{R_{p}}
$$

The specific power was calculated by two methods. Method one considered the power and production rate over the entire batch run, from distiller startup to shutdown. Method two considered the power and production rate at steady-state operation only, see description of steady-state operation above.

\section{Percent Recovery Rate}

The percent recovery, or condensate recovered from the initial solution processed, is given by

$$
\% R=\frac{G_{p}}{G_{f}} \times 100
$$

where $G_{f}$ and $G_{p}$ are the weight of the feed consumed and total distillate produced, respectively. The total distillate includes the volumes collected in the vapor traps during batch processing.

\section{RESULTS AND DISCUSSION}

\section{ELS Test Solution 1}

CDS operations for solution 1 testing were begun May 6, 2009, and continued through June 15, 2009. Over the course of the test, 27 full test runs were completed. The average batch size was $14 \pm 2 \mathrm{~kg}$. The distiller operated approximately 97 hours during the test. The performance of the CDS was considered generally nominal. Test run 28 was terminated prematurely due to issues related to distiller motor power and noise. A posttest investigation of the distiller unit found light contamination and/or corrosion of the bearings. Over 27 test runs completed, the total amount of ELS solution 1 processed was approximately $377 \mathrm{~kg}$. The processed influent resulted in recovery of approximately $352 \mathrm{~kg}$ of distillate and $26 \mathrm{~kg}$ of brine. The predicted recovery rate was $93.4 \pm 0.7$ percent. The average mass of influent, product, and brine processed per batch was approximately 14,13 , and $1 \mathrm{~kg}$, respectively. The system mass balance, calculated by summing the total mass of distillate and brine collected and dividing by the total influent processed, was 100.2 percent. Power consumption for the CD, THP, and vacuum pump over the batch run averaged $84 \mathrm{~W}, 287 \mathrm{~W}$, and $58 \mathrm{~W}$, respectively, and $93 \mathrm{~W}, 281 \mathrm{~W}$, and $26 \mathrm{~W}$ at steady state. The average batch processing rate was $3.5 \pm 0.2 \mathrm{~kg} / \mathrm{hr}$ and increased to $4.1 \pm 0.1 \mathrm{~kg} / \mathrm{hr}$ when averaged over steady-state operation. Accordingly, the average specific energy calculated for the batch drops from $112 \pm 2 \mathrm{~W}-\mathrm{hr} / \mathrm{kg}$ to $99 \pm 6 \mathrm{~W}-\mathrm{hr} / \mathrm{kg}$ during steady state. It is important to note that the system was not optimized during testing. Condensation in the vacuum lines and loss of accurate pressure feedback often resulted in excess vacuum operation. When considering only the $\mathrm{CD}$ and THP, specific energy consumption was approximately $92 \pm 2 \mathrm{~W}-\mathrm{hr} / \mathrm{kg}$. Several key parameters of the thermodynamic performance data from test series are summarized in Table 1.

A summary of water quality data from the solution 1 test series is shown in Table 2. Data includes the averages $(n=27)$ of major contaminant categories, including $\mathrm{pH}$, conductivity $(\mathrm{k})$, turbidity, TOC, TIC, TN, and the averaged sums of anions/cations ( $\sum$ ions) and metals $\sum \mathrm{M}$ etals). The ions and metals used in each summation are provided in the Table 2 references. As a general trend, water quality is observed to 
significantly improve from influent to distillate. The improvements in distillate water quality are evidenced by the increase in $\mathrm{pH}$; the decrease in conductivity, TOC, TN, and turbidity; and decreases in the summed average of ions and metals. The scaled improvements in water quality can be correlated to a concomitant change in each of the water quality parameters associated with the brine. For conservative and quasiconservative parameters $-\mathrm{K}$, TOC, TN, and $\Sigma$ ion $\mathrm{s}$ - the concentration changes in the brine are in accord with the predicted recovery rates established by gravimetric analysis. For example, a recovery predicted by the ratio-based change in conductivity, feed over brine, was calculated to be $93.5 \pm 2$ percent versus the gravimetric-based estimate of $93.4 \pm 0.7$ percent. Ratio-based recoveries of the brine using TOC, TN, and $\Sigma$ ions yield similar estimates. These data suggest little carryover of the associated contaminants to the distillate. This suggestion is further demonstrated by the efficiency of removal, which was greater than 99 percent as measured from influent to distillate (Table 2). Removal efficiency of log transformed $\mathrm{pH}$ measurements, data not shown, is greater than 98 percent. Less conservative parameters include turbidity and metals. Such observations are likely due to the complex nature of brines, which affect both solution chemistry and measurement accuracy. Metal contamination from components downstream of the distillation process also may affect the observed removal efficiencies.

\section{ELS Test Solution 2}

CDS operations for test solution 2 began July 8, 2009, and continued through August 19, 2009. Over the course of testing, 43 test runs were completed. The average batch size per run was $28 \pm 1 \mathrm{~kg}$. A larger batch size was selected to account for the three-fold increase in loading rate for test solution 2 versus test solution 1 . The distiller was operated for approximately 245 hours during the test series. Testing was again stopped early due to issues related to motor power and distiller noise. Post test analysis found several potential sources of noise, including: possible rub points within the distiller, light contamination of the bearings, and lack of sufficient restraint of the bearing to the distiller shaft. However, the overall disassembly investigation suggested that the operational integrity of the distiller was sound when solution 2 testing was stopped. In addition, the heat transfer surfaces of the unit were observed to be visibly clean, suggesting no significant scale and/or fouling issues of these surfaces over the course of the test.

Over the 43 test runs completed, the total mass of ELS test solution 2 processed was approximately 1190 $\mathrm{kg}$. The processed influent resulted in recovery of approximately $1082 \mathrm{~kg}$ of distillate and $116 \mathrm{~kg}$ of brine. The average mass of influent, product, and brine processed per batch was approximately $28 \mathrm{~kg}, 25 \mathrm{~kg}$, and 2.7 $\mathrm{kg}$, respectively. The recovery rate predicted based on the 43-batch run average was $90.3 \pm 0.5$ percent. The process stream masses were calculated by summing the total mass of distillate and brine collected and dividing by the total influent processed. The process stream mass balance was predicted at 99.9 percent.

For test solution 2, the THP was run at a higher supplied power, increasing the targeted processing rate from 4 to $5 \mathrm{~kg} / \mathrm{hr}$. Again, this was done to account for the higher daily processing load associated with test solution 2. In addition to an increase in batch size, processing times also were required to increase. Power consumption for the CD, THP, and vacuum pump over the batch run averaged $85 \mathrm{~W}, 339 \mathrm{~W}$, and $93 \mathrm{~W}$, respectively. At steady state, the power consumption was $93 \mathrm{~W}, 281 \mathrm{~W}$, and $26 \mathrm{~W}$ for the three components, respectively. The average batch processing rate was $4.4 \pm 0.1 \mathrm{~kg} / \mathrm{hr}$. This value increased to $5.2 \pm 0.1 \mathrm{~kg} / \mathrm{hr}$ during steady-state operation. Accordingly, the average specific power calculated for the batch drops from $117 \pm 2 \mathrm{~W}$-hr/kg to $106 \pm 2 \mathrm{~W}-\mathrm{hr} / \mathrm{kg}$ during steady state. Specific energy consumption when considering only the CD and THP is approximately $94 \pm 1 \mathrm{~W}-\mathrm{hr} / \mathrm{kg}$. As with ELS test solution 1, it is important to note that the system was not optimized during testing; it is predicted that additional efficiencies in specific energy can be gained. Several key parameters of the thermodynamic performance data from test series 2 are summarized in Table 1.

A summary of water quality data from the ELS test solution 2 test series is shown in Table 2. Data includes the averages $(\mathrm{n}=43)$ of major contaminant categories, including $\mathrm{pH}$, conductivity $(\mathrm{k})$, turbidity, TOC, TIC, TN, and the averaged sums of anions/cations $\sum$ ions) and metals ( $\sum$ Metals). As with test solution 1, water quality is observed to improve significantly from influent to distillate. The improvements in distillate water quality are evidenced by the increase in $\mathrm{pH}$ and the decrease in conductivity, TOC, TN, turbidity, and the summed average of ions and metals. The scaled improvements in water quality are correlated to a concomitant change in concentration for each of the water quality parameters associated with the brine. For conservative/quasi-conservative parameters - K, TOC, TN an $\Phi$ ions - the ratios of the concentration changes, brine to influent, are in accord with the predicted recovery rates established by gravimetric analysis. The average recovery predicted by the ratio-based change in $\mathrm{K}, \mathrm{TOC}, \mathrm{TN}$ and $\sum$ ions, feed over brine, for example, is $89.8 \pm 1.4$ percent versus the gravimetric-based estimate of $90.3 \pm$ 
0.5 percent. These data suggest little carryover of the associated contaminants to the distillate. Similar to test solution 1 a high efficiency of removal, greater than 99 percent as measured from influent to distillate, was observed for most measured water parameters.

Table 1. Summary of Thermodynamic Performance Data

\begin{tabular}{|c|c|c|}
\hline Parameter & ELS Test Solution 1 & ELS Test Solution 2 \\
\hline Solution Composition ${ }^{*}$ & $\begin{array}{c}56.6 \% \text { humidity condensate, } \\
43.3 \% \text { urine }\end{array}$ & $\begin{array}{c}18.3 \% \text { humidity condensate } \\
14.0 \% \text { urine } \\
67.7 \% \text { hygiene water }\end{array}$ \\
\hline Influent processed, $\mathrm{kg}$ & $381(\text { target }-414)^{\dagger}$ & $1198(\text { target }-1283)^{\dagger}$ \\
\hline Production rate, $\mathrm{kg} / \mathrm{hr}$ & $4.1 \pm 0.1 @ 300 \mathrm{~W}$ to THP & $5.2 \pm 0.1 @ 400 \mathrm{~W}$ to THP \\
\hline Recovery rate, \% & $93.4 \pm 0.7$ (target -93.5$)$ & $90.3 \pm 0.5($ target -90.0$)$ \\
\hline $\begin{array}{l}\text { Specific Energy }{ }^{\ddagger} \\
\text { W-hr/kg }\end{array}$ & $99 \pm 6$ & $106 \pm 2$ \\
\hline
\end{tabular}

Table 2. Summary of Water Quality Data

\begin{tabular}{|c|c|c|c|c|}
\hline Parameter & Influent & Distillate & Brine & \% Removal \\
\hline \multicolumn{5}{|c|}{ ELS Test Solution 1} \\
\hline $\mathrm{pH}$ & $2.22 \pm 2 \%$ & $4.03 \pm 1.3 \%$ & $1.7 \pm 26 \%$ & - \\
\hline Cond. (mS/cm) & $9.3 \pm 3 \%$ & $0.04 \pm 6 \%$ & $146 \pm 12 \%$ & $>99$ \\
\hline Turb. (NTU) & $3.3 \pm 0.4 \%$ & $0.4 \pm 11 \%$ & $15 \pm 30 \%$ & $>85$ \\
\hline $\mathrm{TOC}(\mathrm{mg} / \mathrm{L})$ & $1586 \pm 20 \%$ & $18 \pm 12 \%$ & $25,064 \pm 26 \%$ & $>98$ \\
\hline TIC (mg/L) & $<0.5$ & $<0.5$ & $<0.5$ & - \\
\hline $\mathrm{TN}(\mathrm{mg} / \mathrm{L})$ & $1844 \pm 11 \%$ & $0.9 \pm 8 \%$ & $26,620 \pm 13 \%$ & $>99$ \\
\hline$\sum$ Ions $(\mathrm{mg} / \mathrm{L})$ & $5430 \pm 4 \%$ & $3.9 \pm 7 \%$ & $92,690 \pm 8 \%$ & $>99$ \\
\hline$\sum$ Metals (mg/L) & $1.0 \pm 1.7 \%$ & $0.05 \pm 5 \%$ & $8.3 \pm 1 \%$ & $>95$ \\
\hline \multicolumn{5}{|c|}{ ELS Test Solution 2} \\
\hline $\mathrm{pH}$ & $2.33 \pm 0.1 \%$ & $4.28 \pm 0.1 \%$ & $1.7 \pm 5 \%$ & - \\
\hline Cond. (mS/cm) & $5.3 \pm 0.2 \%$ & $0.03 \pm 11 \%$ & $55 \pm 4 \%$ & $>99$ \\
\hline Turb. (NTU) & $38 \pm 44 \%$ & $0.7 \pm 21 \%$ & $195 \pm 27 \%$ & $>98$ \\
\hline $\mathrm{TOC}(\mathrm{mg} / \mathrm{L})$ & $820 \pm 17 \%$ & $9 \pm 10 \%$ & $8115 \pm 22 \%$ & $>98$ \\
\hline TIC (mg/L) & $<0.5$ & $<0.5$ & $<0.5$ & - \\
\hline $\mathrm{TN}(\mathrm{mg} / \mathrm{L})$ & $660 \pm 11 \%$ & $0.7 \pm 13 \%$ & $5433 \pm 24 \%$ & $>99$ \\
\hline$\sum$ Ions (mg/L) & $2412 \pm 16 \%$ & $20 \pm 18 \%$ & $26,500 \pm 9 \%$ & $>99$ \\
\hline$\sum$ Metals $(\mathrm{mg} / \mathrm{L})$ & $0.5 \pm 16 \%$ & $0.1 \pm 17 \%$ & $4 \pm 18 \%$ & $>80$ \\
\hline
\end{tabular}




\section{General Test Observations}

Solution 1 differs from solution 2 mainly by dilution of the urine and humidity condensate with approximately 67-percent hygiene water. The hygiene waste stream itself is greater than 98-percent water, but it introduces some unique low-level contaminants associated with the personal care products, e.g., surfactants, oils, and insoluble abrasives associated with the soap, toothpaste, and shave cream. The hygiene water also introduces soiling compounds in the form of human-generated oils, dirt, and dander. These compounds, although in low concentration, can, and have been found to, affect the solution chemistry. The products used in this study were down-selected based on testing by the ELS Project Office to find acceptable products with minimal impacts on the solution chemistry, mainly products with compounds which appeared to demonstrate solubility when present in the mixed waste streams. The dilution effects of hygiene water should theoretically lead to higher water recovery rates for solution 2 than solution 1 . In practice, solution 2 revealed the presence of solids in the unprocessed waste streams. Visual observation of solution 2 also indicated evidence of precipitation at lower recovery rates than observed for solution 1 . The effect of solids on the distillation systems under study are largely unknown. Therefore, recovery rates were selected based on a conservative approach aimed at limiting the introduction and/or formation of solids within these systems.

For the general compounds in both solutions, sulfate and potassium were the predominate inorganic species, accounting for approximately 50 percent and 20 percent of the ion mass, respectively, as measured by IC. Other representative ions, with concentrations between 4 and $14 \%$ of the total ion mass per solution, were chloride, sodium, and phosphate. Magnesium, calcium, and ammonium-nitrogen were also detected at concentrations of $2 \%$ or less of the respective ion masses. Approximately 85 percent of the sulfate and 50 percent of the potassium is assumed to be contributed by the pretreatment chemical, Oxone. The remaining sulfate and other significant ions were contributed primarily by the urine component of the mixed test solution. With the exception of chloride ion, measured at $1.5 \pm 10$ percent $\mathrm{mg} / \mathrm{L}$, all ions measured by IC were predominately below detection limits in the distillate from both test solutions. The disproportionate presence of low concentrations of chloride in the distillate relative to other ions suggests possible low-level co-distillation of hydrochloric acid gas. Distillate from both test solutions also exhibited the presence of a slight bleach-like odor. Preliminary analysis of test solution 2 indicated the presence of low concentrations of both total and free chlorine in the distillate water samples. The co-distillation of chlorine gas, formed by the oxidation of chloride ion in the influent waste stream by Oxone, is a hypothesized pathway for such observations. In general, the salt concentrations for the influent waste streams contributed by urine were considered on the low end of that expected for human donors. This consideration could have influence on the ultimate water recovery rate end-points selected for each test solution.

Average metal concentrations analyzed by ICP-MS analysis were found to be generally low to undetectable. The metal of highest average concentration was zinc, representing approximately 80 to 85 percent of the total metals measured in each test solution, or approximately 850 and $380 \mu \mathrm{g} / \mathrm{L}$, respectively, for solution 1 and 2. Nickel, chromium, and copper were also detected at concentrations between 50 and 20 $\mu \mathrm{g} / \mathrm{L}$. Zinc and nickel were found to be contributed mainly by the humidity condensate, purportedly due to corrosion of the heat exchanger used for collection. ICP-MS analysis of the individual waste streams (data not provided) suggested that the other detectable metals were contributed primarily by urine. Removal efficiencies for the metals were between 80 and 90 percent, suggesting either contamination downstream of the distillation process (e.g., contamination by metal storage tanks, trimming heat exchanger) or measurement inaccuracy associated with the low levels of metals present and the complex nature of the process streams.

Detailed organic analysis was done on three test samples from both the solution 1 and 2 test series. The predominate organic species, by several orders of magnitude, was urea, a major organic constituent of urine. However, the reported values were lower, by approximately 80 percent, relative to the typical concentration range in urine, between 13 to $40 \mathrm{mg} / \mathrm{L}^{11,12}$. The use of diluted urine has been noted as a possible consequence of a limited and unrestricted donor pool. Other potential mechanism for the low urea concentrations are being investigated including solution chemistry and measurement techniques. Interestingly, if the urea concentrations in urine are assumed, based on the typical concentration in urine and considering all dilution effects, the organic concentrations in the influent would be in accord with values measured by TOC analysis. Despite the low concentrations of urea, removal efficiency was still predicted to be greater than 99 percent. Of the other organic species present (i.e., those with concentrations greater than $1000 \mu \mathrm{g} / \mathrm{L}$, such as ethanol, methanol, 1,2-propanediol, 1,2-ethanediol, acetate), removal efficiencies were typically low, in some cases less than zero. The low removal efficiencies likely reflect the volatile to semi-volatile nature of the organics. Using the complete set of compounds measured in the distillate, the estimated total organic carbon 
concentrations are in accord with the average values measured by TOC analysis, $19 \mathrm{mg} / \mathrm{L}$ predicted versus 18 $\mathrm{mg} / \mathrm{L}$ measured for test solution 1 , and $11 \mathrm{mg} / \mathrm{L}$ predicted versus $9 \mathrm{mg} / \mathrm{L}$ measured for solution 2 .

Solids analysis was performed on three test samples from both the solution 1 and 2 test series. The data indicated a high degree of variability in the measured values. The total solids measured for three samples from test solution 1 and 2 influents were $6.2 \pm 20$ percent and $3.2 \pm 32$ percent g/L, respectively. A high degree of removal efficiency, greater than 90 percent from influent to distillate, was observed for both test solutions. In addition, ratio-based predictions of recovery, average influent total solids over brine, predict recoveries of approximately 94 percent for test solution 1 and 89 percent for solution 2. ELS test solution 2 influent waste streams were characterized by the presence of visible solids. At least some fraction of the solids was observed to settle out of the solution over the course of a single batch run, 5 to 6 hours in duration. The visible presence of solids was observed in the brines from both test solutions. For test solution 1 the brine solids were observed as a light slow settling of fine white material. The solids from the solution 2 brine settled rapidly, accumulating a highly visible layer of grayish-white material. The solids are currently being analyzed. The impact of the solids on the CDS and the distillation process, if any, are at present unknown.

The final measurement taken was surface tension. Analyses were performed on three test samples from both the solution 1 and 2 test series. The surface tension of the influent samples for solution 1 and 2 was $51 \pm$ 2 and $28 \pm 0.8$ millinewton per meter $(\mathrm{mN} / \mathrm{m})$, respectively. The average brine surface tension dropped to $41 \pm 2 \mathrm{mN} / \mathrm{m}$ for solution 1, but exhibited almost no change for solution $2,28 \pm 2 \mathrm{mN} / \mathrm{m}$. For both solutions, the urine itself contains surface-activated agents that lower the surface tension. In addition, to solution 2 are added several surface-activated agents in the form of the personal hygiene products. For solution 1, the surface tension effect is greater for the brine due to the inherent concentration effect from the distillation process. For solution 2, the data indicates the critical micelle concentration was reached in the feed, resulting in no effective change in surface tension with subsequent concentration of surfactants in the brine. The average surface tension rises for the distillate samples of both test solutions to $69 \pm 3 \mathrm{mN} / \mathrm{m}$ in solution 1 and to $57 \pm 8 \mathrm{mN} / \mathrm{m}$ in solution 2 . These distillate surface tension values predict closer to that of deionized water, $\approx 73$ to $78 \mathrm{nM} / \mathrm{m}$, lending further evidence as to the efficient treatment of wastewater effected by the CDS process.

\section{Additional Considerations}

As part of the thermodynamic analysis, a comparison of the hot and cold loop thermal loads is intended to be performed for both test series. This work was not completed at the time of this report. As a consideration of thermal loading, the current estimate of waste heat absorbed by the trimming heater during ELS solution 1 testing was approximately $230 \mathrm{~W}$. Currently the thermal cooling energy supplied by the chiller cart system is approximately $600 \mathrm{~W}$. Further optimization of thermal loading in the CDS is a recommended area for system improvement; however, processing requirements should first be established. Currently, the role of supplying cooling media to the trimming heat exchanger is considered under the present assumptions to be a spacecraft function, not a subassembly component of the CDS.

It should also be considered that the principle function of the CDS is as a primary processor. As with all current primary processing technologies, it is expected that the water will need to undergo some form of additional purification prior to consumption. The development goal for the primary processor should be to produce purified water as close to the selected potable water standards as possible and within the performance boundaries of the processing technology. Table 3 provides limited data on the fiscal year 2009 (FY09) performance test results of the CDS demonstration unit relative to what the authors consider a reasonable estimate of potable water quality standards for future long-duration missions. Sample values were estimated from human system integration standards proposed for and used in current and future NASA space programs. For most parameters tested, the data shows fairly close adherence of the current CDS demonstration unit to the water quality estimates. 
Table 3. CDS Distillate Water Quality Compared to Example Potable Water Standard Parameters for Future Space Exploration Programs*

\begin{tabular}{lcccc}
\hline \multicolumn{1}{c}{ Parameter } & Max & $\begin{array}{c}\text { Test Solution 1 } \\
(\mathbf{n}=\mathbf{2 7})\end{array}$ & $\begin{array}{c}\text { Test Solution 2 } \\
(\mathbf{n}=\mathbf{4 3})\end{array}$ & Unit \\
\hline Turbidity & 11 & $0.36 \pm 0.04$ & $0.72 \pm 0.15$ & $\mathrm{NTU}$ \\
Total Solids & $100-500$ & $20 \pm 23$ & $70 \pm 125$ & $\mathrm{mg} / \mathrm{L}$ \\
$\mathrm{pH}$ & $5.5-9.0$ & $4.0 \pm 0.1$ & $4.3 \pm 0.1$ & $\mathrm{~N} / \mathrm{A}$ \\
Total Organic Carbon & $0.5-3$ & $18 \pm 2$ & $9 \pm 1$ & $\mathrm{mg} / \mathrm{L}$ \\
Ammonia & $0.5-1$ & $<0.5$ & $<1.8^{\dagger}$ & $\mathrm{mg} / \mathrm{L}$ \\
Chloride & $200-250$ & $1.5 \pm 0.2$ & $1.5 \pm 0.6$ & $\mathrm{mg} / \mathrm{L}$ \\
Potassium & 340 & $<1.5$ & $<1.6$ & $\mathrm{mg} / \mathrm{L}$ \\
Cadmium & $0.005-0.01$ & $<0.01$ & $<0.02$ & $\mathrm{mg} / \mathrm{L}$ \\
Chromium & 0.05 & $<0.01$ & $<0.02$ & $\mathrm{mg} / \mathrm{L}$ \\
Copper & 1.0 & $<0.01$ & $<0.01$ & $\mathrm{mg} / \mathrm{L}$ \\
Iron & 0.3 & $<0.01$ & $<0.01$ & $\mathrm{mg} / \mathrm{L}$ \\
Lead & 0.05 & $<0.01$ & $<0.02$ & $\mathrm{mg} / \mathrm{L}$ \\
Manganese & 0.05 & $<0.01$ & $<0.02$ & $\mathrm{mg} / \mathrm{L}$ \\
Mercury & $\mathrm{NM}$ & $\mathrm{NM}$ & $\mathrm{mg} / \mathrm{L}$ \\
Nickel & $0.0005-0.002$ & $<0.015$ & $<0.01$ & $\mathrm{mg} / \mathrm{L}$ \\
Silver & $0.05-1.7$ & $<0.01$ & $<0.01$ & $\mathrm{mg} / \mathrm{L}$ \\
Zinc & $0.05-0.6$ & $<0.03$ & $<0.04$ & $\mathrm{mg} / \mathrm{L}$ \\
Selenium & 5.0 & $<0.01$ & $<0.02$ & $\mathrm{mg} / \mathrm{L}$ \\
Iodine & 0.01 & $\mathrm{NM}$ & $\mathrm{NM}$ & $\mathrm{mg} / \mathrm{L}$ \\
\hline
\end{tabular}

*Sample values are estimated from human system integration standards proposed for and used in current and future NASA space programs. NM - not measured. ${ }^{\dagger}$ Two samples out of 43 had detectable levels of ammonia at reported values of 0.83 and $1.7 \mathrm{mg} / \mathrm{L}$. Metal and Ion values greater than 0.01 and $0.5 \mathrm{mg} / \mathrm{L}$, respectively, indicate instances of detection slightly greater than the lower detection limit of the instrument used for analysis. Typically the frequency of detection was less than 25 percent of respective sample sets.

\section{Distiller Disassembly}

The cascade distillation unit was disassembled after completion of the solution 1 testing. The unit was found to be generally very clean, with no visible signs of wear observed. Some discoloration of the Pitot tube, transfer tube, and small and large bearings were noted. The bearings were revealed to have minor corrosion of the metallic race, as well as some contamination from the non-metallic cage material. Bearing wear was considered light. It was suggested that the bearings might be serviced returned to use without issue. A decision was made, however, to replace the bearings with a fully ceramic design. The unit was reassembled and returned to JSC for continued testing.

Following completion of solution 2 testing at JSC, the cascade distillation unit was again disassembled. Similar to solution 1 disassembly results, the unit was found to be generally clean particularly with regard to the heat transfer surfaces (see Figure 3). However, evidence of light mechanical wear was observed, including metal-to-metal rubbing between a Pitot tube and the rotor assembly. There was also an indication

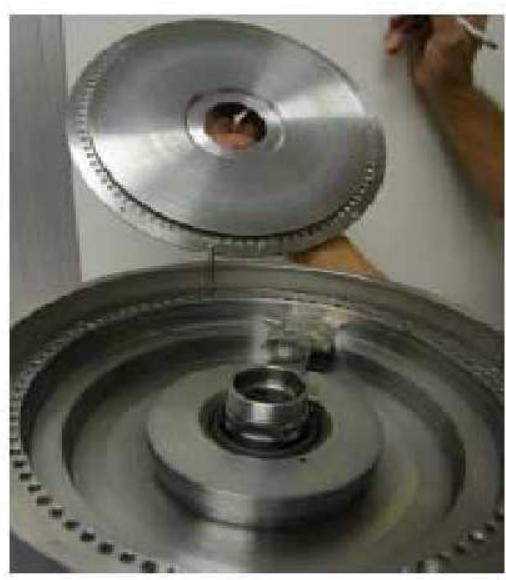

Figure 3. Example of Clean Heat Transfer Surfaces Following Solution 2 Testing of slipping between the bearing inner race and the motor shaft and light bearing wear in both the bearing assemblies. The wearing of these components was likely the source of the observed noise noted at the end of solution 2 testing. In addition, a light coating of white material was found on several liquid/gas separators. The presence of the material was greatest toward the stage V evaporator. Sufficient material was not recovered for analysis; however, calcium sulfate precipitate is suspected as a possible cause. A plan to address the issues noted has been provided to ELS as part of a technology development plan. 


\section{CONCLUSIONS}

A substantial amount of data was collected on the performance of the CDS, as set forth by the ELS distillation comparison test. This was accomplished by processing $377 \mathrm{~kg}$ of ELS test solution 1 to 93.4percent recovery and $1190 \mathrm{~kg}$ of ELS test solution 2 to 90.3 -percent recovery. The mass of test solution processed represents approximately 27 and 28 equivalent lunar days, with a crew of four, for each respective test stream. These results accomplished as part of CDS testing are considered significant, as the CDS was developed as a small batch demonstration system prior to the establishment of formal requirements for the ELS distillation comparison test. In addition, the CDS is still considered to be at a low technology readiness level, particularly with regard to packaging the core technology into a functional subsystem. All relevant test data has been supplied to the System Analysis Modeling and Integration (SIMA) group at NASA JSC. SIMA will be responsible for further analysis of and comparison to the CDS data relative to the other ELS distillation technologies tested under a similar protocol. The data collected during the CDS test program has been applied to a technology development plan provided to ELS. To date, no significant technical impediments are foreseen for continued development of the technology. The CDS design is scalable and adaptable to a broad range of mission scenarios. The functionality of the core distillation technology has been shown through test, and it is expected that the CDS will trade competitively against other ELS distillation technologies. The authors believe that CDS represents a viable and flexible water recovery technology, with promising application to NASA's future exploration programs.

\section{Acknowledgments}

The authors gratefully acknowledge the contribution and efforts of the 3T Control System developers, Pete Bonasso, Jeff Kowing, and Thomas Matthews of the NASA JSC Robotics, Automation, and Simulation Division. The $3 \mathrm{~T}$ Control System is used for autonomous operation of the CDS. ${ }^{13}$ The authors thank Chris Carrier, Letty Vega, Nik Adam, and Michael Casteel of the Engineering and Science Contract Group, as well as David Glock of the NASA JSC AWRSDF for their contributions, insights, and project support. The authors recognize Audry Almengor and Dean Muirhead of the Engineering and Science Contract Group for their committed engineering, analysis, and logistics support during CDS test operations. Finally, the authors acknowledge Jeff McQuillan of ESCG, NASA Exploration Life Support Project, for his tireless efforts to coordinate the many facets of the ELS distillation down-selection task, and to the many scientists, engineers, and staff members who participated in the planning and execution of CDS-related test activities, including Monsi Roman, Layne Carter, Joseph Scott, and Keith Parish of the NASA Marshall Space Flight Center; Mike Flynn and Lance Delzeit of the NASA AMES Research Center; and Molly Anderson, Laura Crenwelge, Rom Allada, and Jannivine Yeh of the NASA JSC Systems Analysis, Modeling, and Integration group.

\section{References}

\footnotetext{
${ }^{1}$ The Vision for Space Exploration, NASA Headquarters Washington, D.C., NP-2004-01-334-HQ, NASA: Feb 2004.

${ }^{2}$ NASA Exploration Systems Architecture Study, Final Report, NASA-TM-2005-214062; NASA: Nov 2005.

${ }^{3}$ Bagdigian, R.M.; Carter, D.L.; and Bedard, J., "Status of the Regenerative ECLSS Water Recovery System," 37th International

Conference on Environmental Systems, Paper No. 2007-01-3100, SAE, Chicago, Illinois, 2007.

${ }^{4}$ Bagdigian, R.M.; Cloud, D.; and Bedard, J., "Regenerative ECLSS Water Recovery and Oxygen Generation Systems," 36th

International Conference on Environmental Systems, Paper No. 2006-01-2057, SAE, Norfolk, Virginia, July 2006.

${ }^{5}$ Carter, D.L.; and Tatara, J.D., "Performance Assessment of ISS Water Processor Assembly Reactor," 34th International

Conference on Environmental Systems, Paper No. 2004-01-2451, SAE, Colorado Springs, Colorado, 2004.

${ }^{6}$ Tomes, K., Long, D., Carter, L., and Flynn, M., "Assessment of the Vapor Phase Catalytic Ammonia (VPCAR) Technology at the MSFC ECLS Test Facility,” 37th International Conference on Environmental Systems, Paper No. 2007-01-3036, SAE, Chicago, Illinois,

${ }^{7}$ O'Rourke, M.E.; Perry, J.L.; and Carter, D.L., “A Water Recovery System Evolved for Exploration,” 36th International Conference on Environmental Systems, Paper No. 2006-01-2274, SAE, Norfork, Virginia, 2006.

${ }^{6}$ Lubman, A.; MacKnight, A.; Rifert, V.; and Barabash, P., "Cascade Distillation Subsystem Hardware Development for Verification Testing," 37th International Conference on Environmental Controls, Paper No. 2007-01-3177, SAE, Chicago, Illinois, July 2007.

${ }^{7}$ Callahan, M.R.; Lubman, A.; MacKnight, A.; Thomas, E.A.; and Pickering, K.D., "Cascade Distillation Subsystem Development Testing," 38th International Conference on Environmental Systems, Paper No. 2008-01-2195, SAE, San Francisco, Calif., 2008.

${ }^{8}$ Callahan, M.R.; Lubman, A.; and Pickering, K.D., "Cascade Distillation Subsystem Development Testing: Progress Toward a Distillation Comparison Test," 39th International Conference on Environmental Systems, Paper No. 2009-01-2401, SAE, Savannah, GA.,

${ }^{9}$ Flynn, M.; and Borchers, B., "Assessment of the Technical Readiness of the Vapor Phase Catalytic Ammonia Removal Process," 33rd International Conference on Environmental Systems, Paper No. 2000-01-2287, SAE, July 2000, Toulouse, France.

${ }^{10} \mathrm{APAH}$. 2006. Standard Methods for the Examination of Water and Wastewater. On-line Edition www.standardmethods.org. Washington DC: American Public Health Association, American Water Works Association, Water Environment Federation.
} 2007. 2009. 
${ }^{11}$ Webb. P., editor, Bioastronautics Data Book, NASA-SP-3006, Section 13, 1964.

${ }^{12}$ Tietz Textbook of Clinical Chemistry and Molecular Diagnostics, $4^{\text {th }}$ edition, C. A. Burtis, E. R. Ashwood, and D. E. Bruns, editors, Elsevier Saunders, St. Louis, MO, 2006. Also, Tietz Fundamentals of Clinical Chemistry, $4^{\text {th }}$ edition, C.A. Burtis and E. R. Ashwood, editors, W. B. Saunders, Philadelphia, PA, 1996

${ }^{13}$ Bonasso, R.P., "A Distributed 3T Control System to Manage Readiness Testing of a Cascade Distiller System," $35^{\text {th }}$ International Conference on Environmental Systems, Paper No. 2008-01-1977, Chicago, Illinois, July 2007. 